\title{
Caffeine and Cannabis Effects on Vital Neurotransmitters and Enzymes in the Brain Tissue of Juvenile Experimental Rats
}

\author{
J.O. Owolabi S.Y. Olatunji A.J. Olanrewaju \\ Department of Anatomy, Ben Carson School of Medicine, Babcock University, Ilisan, Nigeria
}

\section{Keywords}

Caffeine - Cannabis - Cytochrome C oxidase .

Glucose-6-phosphate dehydrogenase - Gamma-amino butyric acid - Glutamate - Dopamine · Brain

\begin{abstract}
Background: Caffeine and cannabis are globally consumed and abused psychoactive substances. While caffeine is legally used in various forms, including in tea and coffee as beverages, it is also consumed in soda and energy drinks as additives. Cannabis, on the other hand, is considered illegal in most countries; albeit, it is being consumed globally particularly by adolescents. Purpose: The adolescent stage marks a critical stage of brain development and maturation. Influences of agents on the brain at this stage may affect neuronal structural and functional attributes. To this end, the current experiment considered the effects of cannabis and caffeine on selected key neurotransmitters and enzymes in the brain tissues after regimented caffeine and cannabis treatment for 21 days. Methods: A total of 72 juvenile Wistar rats that were approximately 40 days old were divided into 6 groups A-F. The group A served as the control. Other groups were administered various dosages of caffeine or cannabis in distilled wa-
\end{abstract}

ter, using oral gavages as follows: group B animals received $100 \mathrm{mg} / \mathrm{kg}$ body weight of caffeine, group C animals received $50 \mathrm{mg} / \mathrm{kg}$ body weight of caffeine, group $D$ animals received $500 \mathrm{mg} / \mathrm{kg}$ body weight of cannabis, group E animals received $200 \mathrm{mg} / \mathrm{kg}$ body weight of cannabis, and group F received a low dose of cannabis ( $200 \mathrm{mg} / \mathrm{kg}$ body weight) plus a low dose of caffeine ( $50 \mathrm{mg} / \mathrm{kg}$ body weight). The animals were killed by cervical dislocation $24 \mathrm{~h}$ after the last administration. The brain tissues were excised and homogenized. The enzymes cytochrome $C$ oxidase and glucose-6-phosphate dehydrogenase were assayed to observe tissue energy metabolism while the neurotransmitters gamma-amino butyric acid (GABA), glutamate, and dopamine were assayed to observe the effects of the psychoactive substances on their activities relative to mental activities. Results: GABA, glutamate, and dopamine were generally higher in the treated groups of animals. The levels of G-6-PDH were higher in all treated animals' brains. Caffeine produced quite more significant effects relative to cannabis and the combination of both increased the level of G-6-PDH significantly. Conclusion: Results showed that caffeine and cannabis influenced the activities of the enzymes and neurotransmitters in the brain. Both stimulants altered brain chemistry relative to the tested enzymes and neurotransmitters.

(c) 2017 S. Karger AG, Basel

\section{KARGER}

(c) 2017 S. Karger AG, Basel
J.O. Owolabi

Department of Anatomy

Ben Carson School of Medicine

Babcock University, Ilisan (Nigeria)

E-Mail olaowolabi001@yahoo.com and owolabijo@babcock.edu.ng 


\section{Introduction}

Caffeine is a methylxanthine with the chemical name that is used globally as a psychoactive agent [1-3] almost without restrictions [4]. Caffeine as a psychoactive substance interacts primarily with adenosine receptors (ARs) in the brain [3]. It elicits its stimulating effects primary by virtue of its interactions with the $A R$; the $A_{1}$ and $A_{2 A}$ receptors have been implicated to play more important roles [3]. It only binds to the $A_{2 B}$ at high doses and the $A_{3}$ receptor is insensitive to caffeine [3]. By this mechanism, it primarily alters neural activities to influence mental activities and performance, resulting in increased mental alertness and wakefulness [3, 5-9]. Excessive quantities of caffeine have also been associated with changes in emotion and motor activities especially in forms of tremor and anxiety among others $[1,3]$. While it has been argued that moderate consumption of caffeine might not produce effects that could translate to anxiety, its use make individuals vulnerable to the risk of manifesting anxiety [10]. Major natural sources of caffeine include coffee, tea, and cocoa while it is a usual additive to soda and soft drinks as well as a number of medicinal drugs [1-3].

Cannabis sativa or cannabis is a plant with psychoactive phytochemicals and it is indigenous to Central Asia and the Indian subcontinent [11]. It is prepared in various forms and consumed especially in its typical marijuana form, which is prepared from the stems, leaves, and dried flower buds of the cannabis plant [12]. Cannabis is used and often abused with a primary goal of altering mental attributes believed by the users to increase their courage and drive. Cannabis, typically taken in forms of leaf smoking or as preparations or extracts of the leaf, contains the active agent cannabinoid THC (delta-9-tetrahydrocannabinol or $\Delta^{9}$-tetrahydrocannabinol). The mechanisms of action of these agents include their interactions with the cannabinoid receptors. To influence neural activities, cannabis would interfere with neurotransmitters' activities. Humans studies had suggested that high cannabis users have as much dopamine as much as non-users, the effects of this neurotransmitter is being blunted in user, thus limiting the reward of pleasure that they experience [13]. Its long-term use is also reported to have potentials to alter the balance of dopamine in the brain [14].

Cannabis would influence brain activities in many brain regions because of the wide distribution of the cannabinoid receptors that THC can bind with; it binds in a similar way as anandamide which produces pleasurable feeling but, in addition to this, it alters other natural functions of these specific brain regions [14]. Short-term ef- fects of cannabis use include distorted perception including touch, sight, sounds, and time as well as cerebellar functions altering balance, posture, and the coordination of movement. Long-term use of the drug can also lead to a series of attitude and personality changes, characterized by a diminished ability to carry out long-term plans, a sense of apathy, decreased attention to appearance and behaviour, and decreased ability to concentrate for longer periods of time. These changes can also include poor performance in school [14].

It is expected that the competitions between the exogenous active psychoactive agents with certain endogenous neurotransmitters for their receptors will alter the states and levels of activities of the endogenous substances. Enzymes will expectedly be influenced as well. This same mechanism is primarily responsible for the changes in neural and mental activities that accompany the use of the substance. While several reports are available on the behavioural changes that accompany the use of these substances, it is important to enrich the literatures on the accompanying in situ biochemical changes. This is important because neural functions depend on the brain's chemical activities premise. This research investigated the changes in the activities of vital neurotransmitters and enzymes toward appreciating the neurochemical changes that accompany the changes in mental or neural activities that are produced by caffeine and cannabis.

Though a number of experiments had studied some of the neurotransmitters and enzymes considered, many of the experiments were not carefully modelled after human uses(s) of the psychoactive agents. The existing collections of literatures did not consider the enzymes and neurotransmitters in the same biological milieu and under the same condition as presented in this work. To this end, this work provides insight into possible dependent relationships in the alterations in the enzymes and neurotransmitters as caused by cannabis and caffeine. It therefore implies that the current investigation differs from others and provides a unique perspective to the subject based on the design and regimen and not necessarily in terms of what was studied.

\section{Methods}

Caffeine and Cannabis Regimen

Anhydrous caffeine was dissolved in distilled water to obtain suitable concentrations as designed in the experimental regimen. Cannabis aqueous extract was prepared by first blending the dried leaves, and then blending the dried leaves in fine powder using a dry blender. The fine powder was thereafter soaked in water for
66

Ann Neurosci 2017;24:65-73 DOI: $10.1159 / 000475895$
Owolabi/Olatunji/Olanrewaju 
about $12 \mathrm{~h}$ and filtered; the substrate was evaporated to dryness, weighed, and then prepared into the mixture of suitable concentrations for the various animal groups.

We had previously worked on these psychoactive agents, and we had performed a series of pilot studies that provided reliable empirical information on the doses; very importantly, observations and technical comparison of real life human consumption scenarios helped our choices of doses. Ethical approval was obtained to carry out the investigation. Also, every activity and procedure was carried out with strict adherence to ethical regulations and institutional standards of research.

\section{Animals Treatment}

Adolescent Wistar rats were allowed to acclimatize. They were housed in the Institutional Animal Holding Facility under suitable environmental conditions and in standard seized cages throughout the duration of treatment. They were divided into 6 groups labeled A-F. Group A served as the control group and the animals were only fed ad libitum throughout the duration of experiment so as to serve as the standard reference for the other groups. Group $B$ animals received a high dose of caffeine $(100 \mathrm{mg} / \mathrm{kg}$ body weight $)$, group C received a low dose of caffeine $(50 \mathrm{mg} / \mathrm{kg}$ body weight), group D received a high dose of cannabis ( $500 \mathrm{mg} / \mathrm{kg}$ body weight), group E received a low dose of cannabis ( $200 \mathrm{mg} / \mathrm{kg}$ body weight), and group $\mathrm{F}$ received caffeine and cannabis at the relatively low doses combined $(50 \mathrm{mg} / \mathrm{kg}$ body weight of caffeine plus 200 $\mathrm{mg} / \mathrm{kg}$ body weight of cannabis). Animals were administered substances daily between the hours of 07:00 and 08:00 using suitable oral gavages.

All activities involving the use, handling, treatment, and management of the experimental animals were carried out in compliance with ethics and standard institutional research practices. The treatments lasted 21 days. Animals were sacrificed by cervical dislocation $24 \mathrm{~h}$ after the last administration. The skulls were dissected and the brain tissues were excised.

\section{Tissue Preparations}

Each animal's brain was excised whole, grossed, and cleaned to remove non-neural tissues. Whole brains were homogenized using automated homogenizer. The homogenate was centrifuged, and the supernatant was collected and treated based on the protocols for enzymes and neurotransmitters.

\section{Enzymes and Neurotransmitters Assays}

Procedure for Cytochrome C Oxidase Assay as a Measure of Normal Tissue Function $[15,16]$

Measurement of cytochrome $\mathrm{C}$ oxidase activity: the absorption of cytochrome $C$ at $550 \mathrm{~nm}$ would change with its oxidation state. This property was the basis for the assay. Cytochrome $\mathrm{C}$ was reduced with dithiothreitol and then reoxidized by the cytochrome $\mathrm{C}$ oxidase. The difference in extinction coefficients (De $\mathrm{mM}$ ) between reduced and oxidized cytochrome $C$ was 21.84 at $550 \mathrm{~nm}$. The oxidation of cytochrome $\mathrm{C}$ by cytochrome $\mathrm{C}$ oxidase is a biphasic reaction with a fast initial burst of activity followed by a slower reaction rate. In this assay, the initial reaction rate was measured during the first $45 \mathrm{~s}$ of the reaction. Total volume of the reaction was $1.1 \mathrm{~mL}$. Spectrophotometer settings following the decrease in absorption at $550 \mathrm{~nm}$ at room temperature $\left(25^{\circ} \mathrm{C}\right)$ using a kinetic program was $5 \mathrm{~s}$ delay, $10 \mathrm{~s}$ interval, and 6 readings. The instrument was set up prior to starting any reaction. The wave- length setting was considered critical and could deviate by no more than $2 \mathrm{~nm}$. No signal was observed with a deviation of $10 \mathrm{~nm}$.

Assay procedure included the addition of $0.95 \mathrm{~mL}$ of $1 \times$ assay buffer to a cuvette and zeros the spectrophotometer. Also, a suitable volume of enzyme solution or mitochondrial suspension was added to the cuvette, bringing the reaction volume to $1.05 \mathrm{~mL}$ with $1 \times$ enzyme dilution buffer. Mixing was by inversion. This was followed by starting the reaction by the addition of $50 \mathrm{~mL}$ of ferrocytochrome $\mathrm{C}$ substrate solution and mixing by inversion. The A550/min was read immediately due to the rapid reaction rate of this enzyme. Background values were expected between 0.001 and $0.005 \mathrm{~A} 550 / \mathrm{min}$. The activity of the sample was calculated.

$$
\begin{aligned}
& \text { Units } / \mathrm{mL}=\mathrm{DA} / \mathrm{min} \times \text { dil } \times 1.1(\text { vol of enzyme }) \times 21.84 \\
& \text { Units } / \mathrm{mL}=\frac{\Delta \mathrm{A} / \mathrm{min} \times \text { dil } \times 1.1}{(\text { vol of enzyme }) \times 21.8}
\end{aligned}
$$

where $\Delta \mathrm{A} / \mathrm{min}=\mathrm{A} / \min _{\text {(sample) }}-\mathrm{A} / \mathrm{min}_{\text {(blank) }}$; dil = dilution factor of enzyme or sample; $1.1=$ reaction volume in $\mathrm{mL}$; vol of enzyme $=$ volume of enzyme or sample in $\mathrm{mL} ; 21.84=\Delta \varepsilon^{\mathrm{mM}}$ between ferrocytochrome $\mathrm{C}$ and ferrocytochrome $\mathrm{C}$ at $550 \mathrm{~nm}$.

Unit definition: 1 unit will oxidize $1.0 \mu \mathrm{mol}$ of ferrocytochrome $\mathrm{C}$ per minute at $\mathrm{pH} 7.0$ at $25^{\circ} \mathrm{C}$.

G-6-PDH Assay as a Marker of Metabolism [17]

This dehydrogenase has dual coenzyme specificity. When assayed under conditions that are optimal for the particular coenzyme, the ratio of observed catalytic activity is NAD/NADP $=1.8$. The reaction velocity is determined by measuring the increase in absorbance at $340 \mathrm{~nm}$ resulting from the reduction of NAD or NADP. One unit reduces $1 \mu \mathrm{mol}$ of pyridine nucleotide per minute at $30^{\circ} \mathrm{C}$ and $\mathrm{pH} 7.8$ under the specified conditions.

\section{Assay Procedure}

The spectrophotometer was adjusted to 340 and $30^{\circ} \mathrm{C}$. Reagents were pipetted into each cuvette as follows: $0.055 \mathrm{M}$ Tris $\cdot \mathrm{HCl}$ buffer, pH 7.8 with $0.0033 \mathrm{M} \mathrm{MgCl}_{2}, 2.7 \mathrm{~mL}$; $0.006 \mathrm{M} \mathrm{NADP}$ (or $0.06 \mathrm{M}$ NAD), $0.1 \mathrm{~mL} ; 0.1 \mathrm{M}$ glucose-6-phosphate, $0.1 \mathrm{~mL}$. Incubation was done in spectrophotometer at $30^{\circ} \mathrm{C}$ for $7-8 \mathrm{~min}$ to achieve temperature equilibration and establish blank rate, if any. This was followed by adding $0.1 \mathrm{~mL}$ diluted enzyme and recording increase in $A_{340} / \mathrm{min}$ for 4-5 min. The $A_{340} / \mathrm{min}$ was calculated from the initial linear portion of the curve.

$$
\text { Units } / \mathrm{mg}=\frac{\Delta \mathrm{A} 340 / \mathrm{min}}{6.22 \times \mathrm{mg} \text { enzyme } / \mathrm{mL} \text { reaction mixture }}
$$

Gamma-Amino Butyric Acid Neurotransmitter Assay as Evaluation of Neurocortical Structural and Functional Integrity [18]

For this assay, tissues were rinsed in ice-cold PBS $(0.01 \mathrm{~mol} / \mathrm{L}$, $\mathrm{pH} 7.0-7.2)$ to remove excess blood thoroughly and weighed before homogenization. The tissues were minced to small pieces and homogenized in 5-10 mL of PBS with a glass homogenizer on ice. The resulting suspension was sonicated with an ultrasonic cell disrupter or subjected to 2 freeze-thaw cycles to break the cell membranes further. After that, the homogenates were centrifugated for $5 \mathrm{~min}$ at $5,000 \mathrm{~g}$. The supernate was removed and assayed. 
Assay Procedure Summary

All reagents, samples, and standards were prepared. Fifty microliters of standard or sample was added to each well, followed by the addition of $50 \mu \mathrm{L}$ prepared Detection Reagent A immediately, shaking and mixing, and incubating $1 \mathrm{~h}$ at $37^{\circ} \mathrm{C}$. It was aspirated and washed 3 times followed by adding $100 \mu \mathrm{L}$ prepared Detection Reagent $\mathrm{B}$, and incubating $30 \mathrm{~min}$ at $37^{\circ} \mathrm{C}$. It was again aspirated and washed 5 times followed by adding $90 \mu \mathrm{L}$ substrate solution, and incubating $15-25 \mathrm{~min}$ at $37^{\circ} \mathrm{C}$. Fifty microliters of stop solution was added and reading at $450 \mathrm{~nm}$ was done immediately.

\section{Calculation of Results}

The assay method employed the competitive inhibition enzyme immunoassay technique, so there is an inverse correlation between gamma-amino butyric acid (GABA) concentration in the sample and the assay signal intensity. The duplicate readings for each standard, control, and samples were averaged; a standard curve was created on log-log or semi-log graph paper, with the log of GABA concentration on the Y-axis and absorbance on the $\mathrm{X}$-axis. Drawing the best-fit straight line through the standard points helped determine value by regression analysis. If samples have been diluted, the concentration read from the standard curve must be multiplied by the dilution factor

Glutamate Neurotransmitter Assay Procedure [19]

First, $10 \mathrm{~mL}$ of the $0.1 \mathrm{M}$ Glutamate Standard was diluted with $990 \mu \mathrm{L}$ of the Glutamate Assay Buffer to prepare a $1 \mathrm{mM}$ standard solution. This was followed by adding $0,2,4,6,8$, and $10 \mu \mathrm{L}$ of the $1 \mathrm{~mm}$ standard solution into a 96 well plate, generating 0 (blank), and 2, 4, 6, 8, and $10 \mathrm{nmol} /$ well standards. Then, Glutamate Assay Buffer was added to each well to bring the volume to $50 \mu \mathrm{L}$. Tissue $\left(1 \times 10^{6}\right)$ was be homogenized in $100 \mu \mathrm{L}$ of the Glutamate Assay Buffer. The samples were centrifuged at $13,000 \mathrm{~g}$ for $10 \mathrm{~min}$ to remove insoluble material. Serum samples $(10-50 \mu \mathrm{L})$ were directly added to wells. Samples were, when necessary, deproteinized with a $10 \mathrm{kDa}$ MWCO spin filter prior to addition to the reaction. (This step mignt be necessary if enzymes in the samples interfered with the assay.) Samples were brought to a final volume of $50 \mu \mathrm{L}$ with Glutamate Assay Buffer. A blank sample for each set of sample was included by omitting the Glutamate Enzyme Mix in the Reaction Mix.

\section{Assay Reaction}

The Reaction Mixes were set up. One hundred microliters of Reaction Mix was required for each reaction (well). Next was adding $100 \mu \mathrm{L}$ of the appropriate Reaction Mix to each of the wells. Wells were mixed using a horizontal shaker or by pipetting and incubate the reaction for $30 \mathrm{~min}$ at $37^{\circ} \mathrm{C}$. Plate was protected from light during the incubation. The absorbance at $450 \mathrm{~nm}\left(\mathrm{~A}_{450}\right)$ was measured.

\section{Calculation of Results}

The background for the assays was the value obtained for the 0 (blank) glutamate standard. Correction was done for the background by subtracting the blank value from all readings. Background values when significant were subtracted from all readings. The values obtained from the appropriate glutamate standards were used to plot a standard curve.
Dopamine Neurotransmitter Assay Procedure [20]

This assay employs the competitive inhibition enzyme immunoassay technique. A monoclonal antibody specific to dopamine has been pre-coated onto a microplate. A competitive inhibition reaction is launched between biotin-labeled dopamine and unlabeled dopamine (standards or samples) with the pre-coated antibody specific to dopamine. After incubation, the unbound conjugate is washed off. Next, avidin conjugated to horseradish peroxidase (HRP) is added to each microplate well and incubated. The amount of bound HRP conjugate is reverse proportional to the concentration of dopamine in the sample. After addition of the substrate solution, the intensity of color developed is reverse proportional to the concentration of dopamine in the sample.

\section{Calculation of Results}

There is an inverse correlation between dopamine concentration in the sample and the assay signal intensity. Average the duplicate readings for each standard, control, and samples. Create a standard curve on log-log or semi-log graph paper, with the log of dopamine concentration on the $\mathrm{Y}$-axis and absorbance on the $\mathrm{X}$-axis. Draw the best-fit straight line through the standard points and it can be determined by regression analysis. Using some plot software, for instance, curve expert 1.30 is also recommended. If samples have been diluted, the concentration read from the standard curve must be multiplied by the dilution factor.

\section{Assay Procedure Summary}

All reagents, samples, and standards were prepared and $50 \mu \mathrm{L}$ standard or sample was added to each well. This was followed by adding $50 \mu \mathrm{L}$ prepared Detection Reagent A immediately. Mixing was done by shaking. Incubation was then allowed for $1 \mathrm{~h}$ at $37^{\circ} \mathrm{C}$, followed by aspirating and washing 3 times. One hundred microliters of prepared Detection Reagent $B$ was added and incubated $30 \mathrm{~min}$ at $37^{\circ} \mathrm{C}$. It was aspirated and washed 5 times followed by adding $90 \mu \mathrm{L}$ substrate solution. Incubation was allowed for 10 $20 \mathrm{~min}$ at $37^{\circ} \mathrm{C}$. Fifty microliters of stop solution was added. Reading at $450 \mathrm{~nm}$ followed immediately.

\section{Statistical Analysis of Results}

The results were expressed as mean \pm SEM for each group. All grouped data were statistically evaluated using GraphPad Prism 5 statistical software using one way analysis of variance. StudentNewman-Keuls post hoc test was used to identify differences between individual means. CI was placed at $95 \%$, so that in all cases a value of $p<0.05$ was considered significant.

\section{Results}

\section{GABA Neurotransmitter Assay Result}

GABA level of the group A (control group) was $0.11 \pm$ 0.0024 . GABA level for group B (caffeine high dose) was significantly $(p<0.05)$ higher than the control at $0.13 \pm$ 0.0012 . GABA level for group C (caffeine low dose) was significantly $(p<0.05)$ higher than the control at $0.13 \pm$ 0.0007 . GABA level for group D (cannabis high dose) was significantly $(p<0.05)$ higher than the control at $0.15 \pm$ 
0.0008. GABA level for group $\mathrm{E}$ (cannabis low dose) was significantly $(p<0.05)$ higher than the control at $0.14 \pm$ 0.0009 . GABA level for group F (cannabis low dose + caffeine low dose) was significantly $(p<0.05)$ higher than the control at $0.14 \pm 0.0027$.

\section{Dopamine Neurotransmitter Assay Result}

Dopamine level of group A (control group) was $0.11 \pm$ 0.0005 . Dopamine level in group B (caffeine high dose) was significantly $(p<0.05)$ higher when compared to the control group at $0.13 \pm 0.0038$. Dopamine level of group B (caffeine low dose) was significantly $(p<0.05)$ higher when compared to the control group at $0.12 \pm 0.0014$. Dopamine level of group C (cannabis high dose) was significantly $(p<0.05)$ higher when compared to the control group at $0.13 \pm 0.0012$. Dopamine level of group D (cannabis low dose) was significantly $(p<0.05)$ higher when compared to the control group at $0.12 \pm 0.0007$. Dopamine level of group $\mathrm{F}$ (cannabis low dose and caffeine low dose) was significantly $(p<0.05)$ higher when compared to the control group at $0.15 \pm 0.0014$.

\section{Glutamate Neurotransmitter Assay Result}

The glutamate level for the group A (control group) was $0.13 \pm 0.0053$. The glutamate level for group B (caffeine high dose) was significantly $(p<0.05)$ higher at $0.17 \pm 0.0025$ when compared with the control group. The glutamate level for group C (caffeine low dose) was significantly $(p<0.05)$ higher at $0.16 \pm 0.0011$ when compared to the control group. The glutamate level for group $\mathrm{D}$ (cannabis high dose) was significantly $(p<0.05)$ higher at $0.16 \pm 0.0007$ when compared to the control group. The glutamate level for group $\mathrm{E}$ (cannabis low dose) was significantly $(p<0.05)$ higher at $0.14 \pm 0.000$ when compared to the control group. The glutamate level for group $\mathrm{F}$ (cannabis low dose + caffeine low dose) was significantly $(p<0.05)$ higher at $0.17 \pm 0.0019$ when compared to the control group.

\section{Cytochrome-C-Oxidase Enzyme Assay}

The cytochrome-C-oxidase level for the group A (control group) was $0.003 \pm 0.0003$. The cytochrome- 6 -oxidase level for group B (caffeine high dose) was slightly higher at $0.05 \pm 0.0$ when compared with the control group. The cytochrome-6-oxidase level for group C (caffeine low dose) was slightly higher at $0.004 \pm 0.0005$ when compared to the control group. The cytochrome-6-oxidase level for group D (cannabis high dose) was slightly higher at $0.006 \pm 0.0006$ when compared to the control group. The cytochrome-6-oxidase level for group E (can-

Caffeine and Cannabis Effects in the Juvenile Experimental Rats nabis low dose) was slightly higher at $0.005 \pm 0.0003$ when compared to the control group. The cytochrome-6-oxidase level for group $\mathrm{F}$ (cannabis low dose + caffeine low dose) was slightly higher at $0.007 \pm 0.0004$ when compared to the control group.

\section{Glucose-6-Phosphate Dehydrogenase}

The G6PDH level for the group A (control group) was $0.009 \pm 0.0006$. The G6PDH level for group B (caffeine high dose) was significantly $(p<0.05)$ higher at $0.173 \pm$ 0.0011 when compared with the control group. The G6PDH level for group C (caffeine low dose) was significantly $(p<0.05)$ higher at $0.015 \pm 0.0004$ when compared to the control group. The G6PDH level for group D (cannabis high dose) was slightly higher at $0.115 \pm 0.0003$ when compared to the control group. The G6PDH level for group E (cannabis low dose) was slightly higher at $0.011 \pm 0.0014$ when compared to the control group. The G6PDH level for group F (cannabis low dose + caffeine low dose) was significantly $(p<0.05)$ higher at $0.25 \pm$ 0.0009 when compared to the control group.

The levels of G-6-PDH were increased in the brain tissues of all the treated animals (Fig. 5). Caffeine produced quite more significant effects relative to cannabis and the combination of both increased the level of G-6-PDH greatly. This suggests that caffeine mechanism might stimulate basal glucose metabolism more, and this is logical as it is widely acclaimed to enhance performance especially at moderate doses. This enzyme is largely associated with glucose metabolism, which is the basic source of energy for the neural tissue; hence, increase in the levels of these enzymes would be an indication of increases in glucose metabolism as well as increases in the rate of neural activities. This would not be unexpected of psychoactive substances that elevate basal metabolism by causing mental arousal, alertness, and increase in performances.

\section{Discussion}

Effects of Caffeine and Cannabis on Neurotransmitters

Caffeine and cannabis generally increased the levels of GABA significantly (Fig. 1). Both of them also caused increases at the higher doses with the GABA levels higher when cannabis was administered. What is basically observed here is that the administration of these 2 psychoactive agents caused increases in the levels of GABA in all the treated groups relative to the untreated control. The implications of this would only be adequately interpreted 
in light of the other parameters. Caffeine reportedly reduced GABA receptor interaction sites [21] and altered their density [22]. While these previous reports gave information on the molecular effects of caffeine on GABA receptors, the current findings show the implications on the quantities and activities of the neurotransmitter. Generally, increase in GABA is associated with increased sleepiness and reduced anxiety, alertness, and memoryrelated functions [23]; however, reduction in receptors interacting sites might nullify or reduce the manifestation of such effects as observed in this investigation.

Dopamine is basically associated with increased alertness and happiness [24] or a state of high mental performance and drive [24]. Both caffeine and cannabis significantly elevated the levels of dopamine in the brain (Fig. 2). The higher doses caused greater increases relative to the control and their counterpart groups that were administered the lower doses. Dopamine has been implicated as a primary neurotransmitter whose activity is influenced by cannabis, the same is true of caffeine as seen in the current investigation; despite their activities involving different mechanisms, both caffeine and cannabis would produce rises in the levels of dopamine acidities in the brain. The combination of cannabis and caffeine greatly increased the dopamine level in the brain. Dopamine would play a key role in determining the nature of either caffeine and cannabis effects on mental attributes especially cognition and memory through long-term potentiation [2527]; and this spectrum-like effect would also include serotonin and epinephrine and acetylcholine.

Glutamate levels were generally higher in the treated groups (Fig. 3). Caffeine however increased glutamate levels more than cannabis and the combination of both of them caused relatively greater increase in the level of glutamate as well. This is not unexpected as glutamate is a most common excitatory neurotransmitter [23].

The ability of THC to inhibit neurotransmitters generally has been reported [28] and this mechanism is being associated with the CB1 receptors which are basically presynaptic $[29,30]$. The neurotransmitters L-glutamate, GABA, noradrenaline, dopamine, 5-HT, and acetylcholine have been specifically implicated [31]. These previous findings showed that the THC in cannabis interfered with key neurotransmitters release and activities in the brains a mean of altering brain functional attributes thought they did not provide quantitative information on neurotransmitters activities which the this particular investigation does. It is important not to be overly presumptive about the pathological implications of the recorded increases in the levels of the studied neurotransmitters as this could

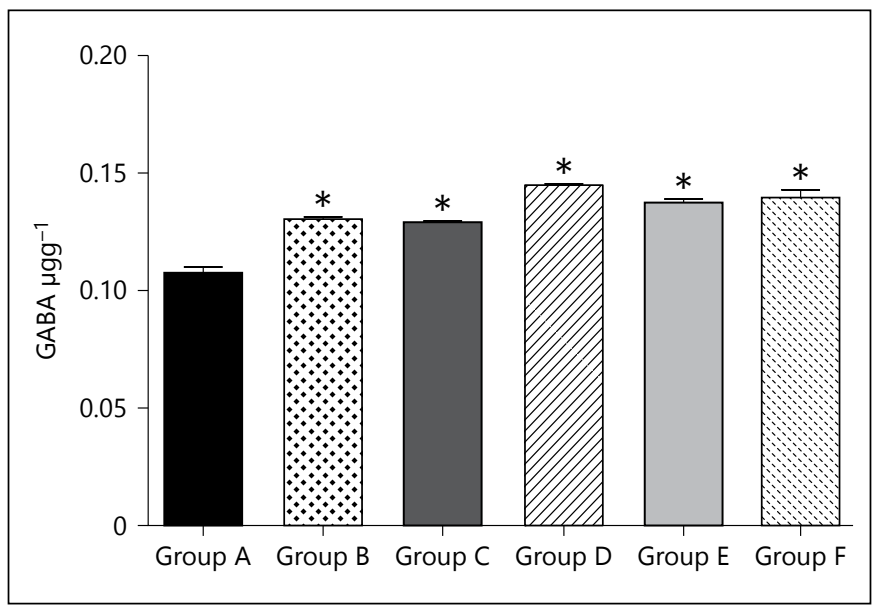

Fig. 1. Bar chart showing the GABA levels of control (group A) and treated groups (groups B-F) after 21 days of treatment. ${ }^{*} p<0.05$ when compared with group A.

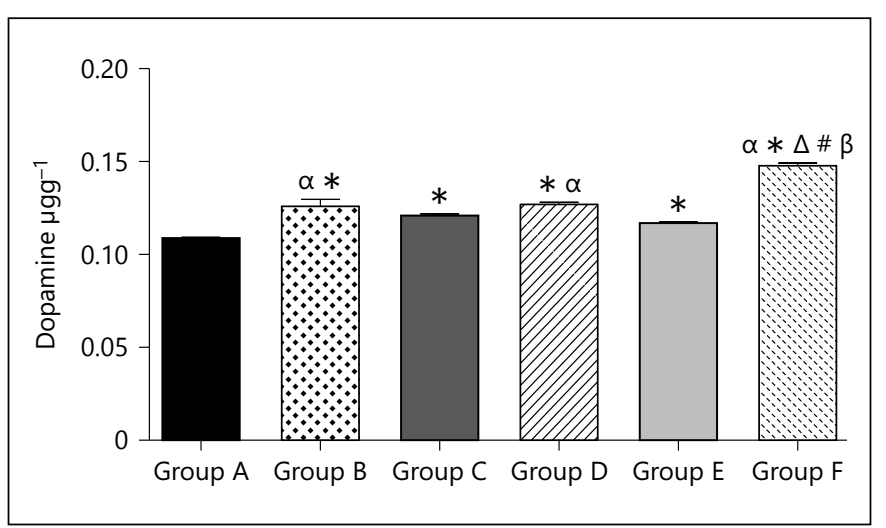

Fig. 2. Bar chart showing the dopamine levels of control and treated groups after 21 days of treatment. ${ }^{\#} p<0.05$ when compared with group $\mathrm{B} ;{ }^{\Delta} p<0.05$ when compared with group $\mathrm{C} ;{ }^{\beta} p<0.05$ when compared with group $\mathrm{D} ;{ }^{\alpha} p<0.05$ when compared with group $\mathrm{E}$.

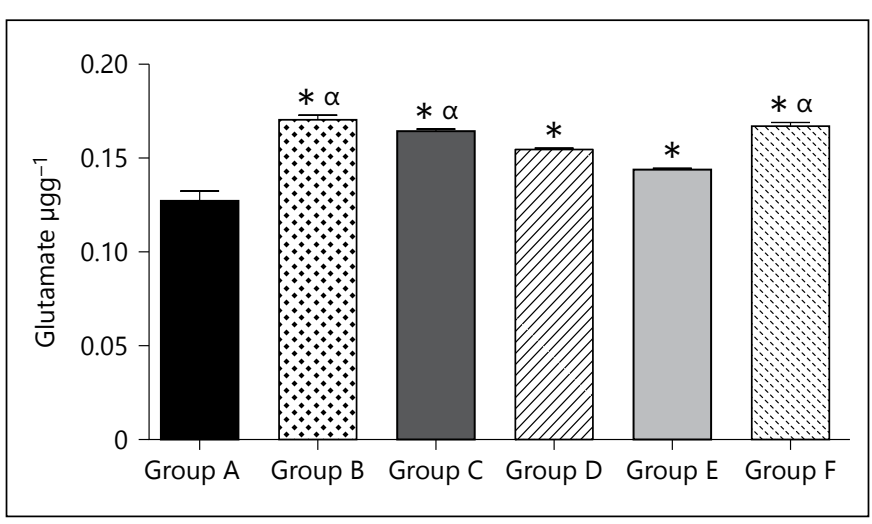

Fig. 3. Bar chart showing the glutamate levels of control and treated groups after 21 days of treatment. ${ }^{*} p<0.05$ when compared with group $\mathrm{A} ;{ }^{\alpha} p<0.05$ when compared with group $\mathrm{E}$. 
point to possible medical potentials if the molecular and biochemical pathways involved are investigated as suggested by some other researchers [32-34].

Results from this study generally indicated the increase in the activities of neurotransmitters assayed for; the levels of dopamine, GABA and glutamate were all higher in the treated groups when compared to the control groups, and this increase could have resulted from the increase in the neural activities in the brain as it is well known that caffeine and cannabis are established neuronal stimulant, as such the nervous activities in the brain cortex is expected to increase. This increase in activity could also bring about an increase in the output of acetylcholine, serotonin (5-HT), dopamine, GABA, and glutamate which are the primary transmitters in the brain and presumably an upregulation of the receptors. This finding supports the previous report that stated that caffeine can by itself enhance 5-HT neuronal firing, the cortical concentration of 5-HT is directly proportional to the concentration of dopamine, GABA, and glutamate, thus explaining the elevated concentration of dopamine, GABA, and glutamate. In addition, a very recent study using both electrophysiological and optogenetical techniques demonstrated a "hyperdirect" excitatory pathway providing a direct excitatory control of 5-HT neurons, most likely important for proper activity of the 5-HT system [35].

Cannabis could also have mediated its effect through this pathway since it also has a direct effect on the limbic system which has been linked to the development of dependency and addiction; this has been shown to increase the secretion of dopamine which would also lead to the increase in the level of GABA and glutamate. This finding supports the view proposed by Bouckaert et al. [36] on synaptogenesis and gliogenesis. However, the combination of cannabis and caffeine mostly caused synergetic response in the level of the neurotransmitters; this implies that both substances produced their individual effects and did not cancel out the effects of one another. This is also expected since they bind primarily to various receptors. Thus, the resultant relative hyper increase is the $\mathrm{cu}-$ mulative effect of their individual influences.

\section{Effects of Caffeine and Cannabis on Enzymes}

The levels of G-6-PDH were increased in the brain tissues of all the treated animals (Fig. 5). Caffeine produced quite more significant effects relative to cannabis and the combination of both increased the level of G-6-PDH greatly. G-6-PDH plays crucial roles in energy metabolism and it is associated with rate of cellular growth, development, and performance [37]. Abnormalities in its

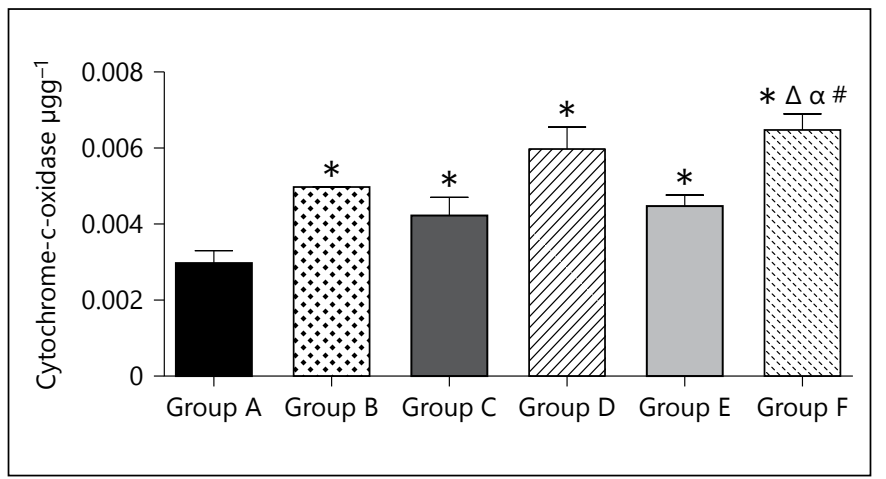

Fig. 4. Bar chart showing the cytochrome-C-oxidase levels of control and treated groups after 21 days of treatment. ${ }^{*} p<0.05$ when compared with group $\mathrm{A} ;{ }^{\#} p<0.05$ when compared with group $\mathrm{B}$; ${ }^{\Delta} p<0.05$ when compared with group $\mathrm{C} ;{ }^{\beta} p<0.05$ when compared with group $\mathrm{D} ;{ }^{\alpha} p<0.05$ when compared with group $\mathrm{E}$.

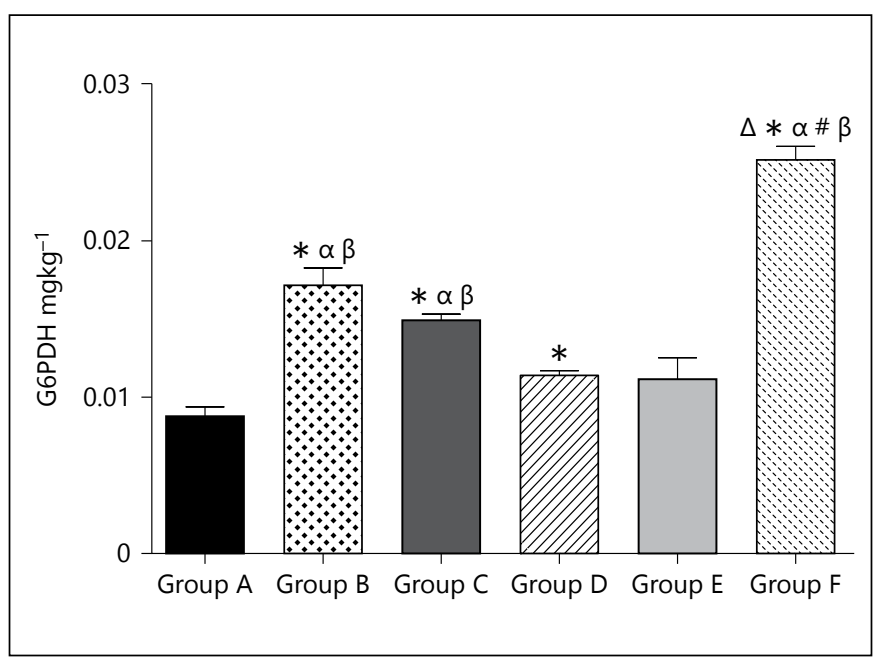

Fig. 5. Bar chart showing the Glucose-6-Phosphate Dehydrogenate levels of control and treated groups after 21 days of treatment. ${ }^{*} p<$ 0.05 when compared with group $A ;{ }^{\#} p<0.05$ when compared with group $\mathrm{B} ;{ }^{\Delta} p<0.05$ when compared with group $\mathrm{C} ;{ }^{\beta} p<0.05$ when compared with group $\mathrm{D} ;{ }^{\alpha} p<0.05$ when compared with group $\mathrm{E}$.

levels may have pathological implications. It also plays vital roles in managing oxidative stress within cells [38]. This suggests that caffeine mechanism might stimulate basal glucose metabolism more, and this is logical as it is widely acclaimed to enhance performance especially at moderate doses. This enzyme is largely associated in glucose metabolism, which is the basic source of energy for the neural tissue; hence, increase in the levels of these enzymes would be an indication of increases in glucose metabolism as well as increases in the rate of neural activities. 
This would not be unexpected of psychoactive substances that elevate basal metabolism by causing mental arousal, alertness, and increase in performances.

Cytochrome $\mathrm{C}$ oxidase levels increased across all animal groups treated with either cannabis or caffeine and the higher dose produced greater increases (Fig. 4). The higher doses produced greater increases in the levels of this enzyme and the combination of both produced the highest increase. This enzyme is a key to synthesizing ATP; hence, it is involved in the derivation of energy for tissue use $[39,40]$. Therefore, the enzyme CCx is vital for optimal cellular functions $[41,42]$. This supports the fact that these agents cause increase in energy metabolism, hence increases in the levels of the activities of the enzyme involved.

From the result of this study, the level of the enzymes cytochrome-6-oxidase and G6PDH in the test groups were significantly higher relative to the control group; this increase could be attributed to the stimulatory effects of caffeine and cannabis which tend to increase metabolic activities generally in the body, this increase in activity would induce an increase in the utility of ATP and hydrolysis of glucose, thus the increase in cytochrome-6-oxidase and G6PDH observed in this study. The combined effects of caffeine and cannabis had synergetic increase in the enzyme levels of animals in that group; this could be due to an increased effect of a combination of caffeine and cannabis on general body metabolism, increasing the use of ATP and hydrolysis of glucose, hence an increase in enzyme level.

\section{Acknowledgment}

We acknowledge the management of Babcock University, Nigeria for the enabling environment to conduct this research.

\section{Author's Contributions}

All authors contributed significantly to the research success. J.O.O. designed the research, supervised, and participated in animal treatment, samples collection, test protocols, and result analysis; and investigation; S.Y.O. co-participated in carrying out the research and in the analysis of results. A.J.O. was primarily involved in the management of resources, writing of the report, and review of final article.

\section{Disclosure Statement}

This article complies with ICMJE.

\section{References}

1 Nehlig A, Daval JL, Debry G: Caffeine and the central nervous system: mechanisms of action, biochemical, metabolic and psychostimulant effects. Brain Res Brain Res Rev 1992;17: 139-170.

2 Nehlig A: Are we dependent upon coffee and caffeine? A review on human and animal data. Neurosci Biobehav Rev 1999;23:563-576.

3 Fredholm BB, Bättig K, Holmén J, Nehlig A, Zvartau EE: Actions of caffeine in the brain with special reference to factors that contribute to its widespread use. Pharmacol Rev 1999;51:83-133.

4 Temple JL: Caffeine use in children: what we know, what we have left to learn, and why we should worry. Neurosci Biobehav Rev 2009; 33:793-806.

5 Brice C, Smith A: The effects of caffeine on simulated driving, subjective alertness and sustained attention. Hum Psychopharmacol 2001;16:523-531.

6 Childs E, de Wit H: Subjective, behavioral, and physiological effects of acute caffeine in light, nondependent caffeine users. Psychopharmacology (Berl) 2006;185:514-523.

7 Roehrs T, Roth T: Caffeine: sleep and daytime sleepiness. Sleep Med Rev 2008;12:153162.
8 Hughes JR, Hale KL: Behavioral effects of caffeine and other methylxanthines on children. Exp Clin Psychopharmacol 1998;6:87-95.

9 Rogers PJ, Heatherley SV, Hayward RC, Seers HE, Hill J, Kane M: Effects of caffeine and caffeine withdrawal on mood and cognitive performance degraded by sleep restriction. Psychopharmacology (Berl) 2005; 179:742-752.

10 Smith A: Effects of caffeine on human behavior. Food Chem Toxicol 2002;40:1243-1255.

11 Mahmoud AE: Marijuana and the Cannabinoids. Humana Press, p 8. ISBN 1-58829-4560 (retrieved May 2, 2011).

12 Hazekamp A, Grotenhermen F: Review on clinical studies with cannabis and cannabinoids 2005-2009. Cannabinoids 2010;5:1-21.

13 Wade L: Hardcore Pot Smoking Could Damage the Brain's Pleasure Center. Science, 2014. http://www.sciencemag.org/news (accessed June 14, 2016)

14 NIH: National Institute on Drug Abuse. Marijuana, 2007. www.drugabuse.gov (accessed June 15, 2016).

15 Lemberg MR: Cytochrome oxidase. Physiol Rev 1969;49:48-121.

16 SIGMA-ALDRICH: Enzymatic Method for Determining Glutamate (Glutamate Assay), 2017. http://www.sigmaaldrich.com.
17 Anderson W, Nordlie R: Glucose dehydrogenase activity of yeast glucose 6-phosphate dehydrogenase. I. Selective stimulation by bicarbonate, phosphate, and sulfate. Biochemistry 1968;7:1479-1485.

18 Elisa GABA Protocol: Elisa Enzyme-linked ImmunosorbentAssay Kit for GammaAminobutyric Acid (GABA). Houston, 2015. www.cloud-clone.us.

19 SIGMA-ALDRICH: Enzymatic Method for Determining Glutamate (Glutamate assay). 2016. http://www.sigmaaldrich.com/technical-documents/protocols/biology/glutamateassay-kit-mak004.html.

20 Atack CV: The determination of dopamine by a modification of the dihydroxyindole fluorimetric assay. Br J Pharmacol 1973;48:699714.

21 Roca DJ, Schiller GD, Farb DH: Chronic caffeine or theophylline exposure reduces gamma-aminobutyric acid/benzodiazepine receptor site interactions. Mol Pharmacol 1988; 33:481-485.

22 Shi D, Nikodijević O, Jacobson KA, Daly JW: Chronic caffeine alters the density of adenosine, adrenergic, cholinergic, GABA, and serotonin receptors and calcium channels in mouse brain. Cell Mol Neurobiol 1993;13:247-261. 
23 Fallows Z: Medlinks - Center for Health Promotion and Wellness at MIT Medical. http:// ocw.mit.edu (accessed June 17, 2016).

24 Mental Health Daily: High Dopamine Levels: Symptoms and Adverse Reactions. http:// mentalhealthdaily.com/2015 (accessed June 17, 2016).

25 Persad, LAB: Energy drinks and the neurophysiological impact of caffeine. Front Neurosci 2011;5:116

26 Myhrer T: Neurotransmitter systems involved in learning and memory in the rat: a meta-analysis based on studies of four behavioral tasks. Brain Res Brain Res Rev 2003;41: 268-287.

27 Acquas E, Tanda G, Di Chiara G: Differential effects of caffeine on dopamine and acetylcholine transmission in brain areas of drugnaive and caffeine-pretreated rats. Neuropsychopharmacology 2002;27:182-193.

28 Schlicker E, Kathmann M: Modulation of transmitter release via presynaptic cannabinoid receptors. Trends Pharmacol Sci 2001; 22:565-572.

29 Gill EW, Paton WD, Pertwee RG: Preliminary experiments on the chemistry and pharmacology of cannabis. Nature 1970;229:134136.

30 Roth SH: Stereospecific presynaptic inhibitory effect of delta9-tetrahydrocannabinol on cholinergic transmission in the myenteric plexus of the guinea pig. Can J Physiol Pharmacol 1978;56:968-975.

31 Iversen L: Cannabis and the brain. Brain 2003; 126(pt 6):1252-1270.

32 Joy JE, Watson SJ, Benson JA: Marijuana and Medicine, Assessing the Science Base. Washington, National Academy Press, 1999.

33 Robson P: Therapeutic aspects of cannabis and cannabinoids. Br J Psychiatry 2001;178: 107-115.

34 Piomelli D, Giuffrida A, Calignano A, et al: The endocannabinoid system as a target for therapeutic drugs. Trends Pharmacol Sci 2000;21:218-224.

35 Pollak DI, Furth D, Xuan Y, Johansson Y, Pozzi L, Silberberg G, Carlen M, Meletis K: A whole-brain atlas of inputs to serotonergic neurons of the dorsal and median raphe nuclei. Neuron 2014;83:663-678.

36 Bouckaert F, Sienaert P, Obbels J, Dols A, Vandenbulcke M, Stek M, Bolwig T: ECT: its brain enabling effects: a review of electroconvulsive therapy-induced structural brain plasticity. J ECT 2014;30:143-151.

37 Tian WN, Braunstein LD, Pang J, Stuhlmeier KM, Xi QC, Tian X, Stanton RC: Importance of glucose-6-phosphate dehydrogenase activity for cell growth. J Biol Chem 1998;273: 10609-10617.
38 Wang YP, Zhou LS, Zhao YZ, Wang SW, Chen LL, Liu LX, Ye D: Regulation of G6PD acetylation by SIRT2 and KAT9 modulates NADPH homeostasis and cell survival during oxidative stress. EMBO J 2014;33:13041320.

39 Yee GM, Tolman WB: Chapter 5, section 2.3: iron-porphyrin/copper complexes as cytochrome C oxidase models'; in Peter MH, Kroneck, Martha E, Sosa T (eds): Sustaining Life on Planet Earth: Metalloenzymes Mastering Dioxygen and Other Chewy Gases. Metal Ions in Life Sciences15. Springer, 2015, pp 153-157.

40 Yoshikawa S, Shimada A, Shinzawa-Itoh K Chapter 4: respiratory conservation of energy with dioxygen: cytochrome $\mathrm{C}$ oxidase'; in Kroneck PMH, Martha E, Sosa T (eds): Sustaining Life on Planet Earth: Metalloenzymes Mastering Dioxygen and Other Chewy Gases. Metal Ions in Life Sciences 15. Springer, 2015, pp 89-130.

41 Khalimonchuk O, Rödel G: Biogenesis of cytochrome C oxidase. Mitochondrion 2005;5: 363-388.

42 Fontanesi F, Soto IC, Horn D, Barrientos A: Assembly of mitochondrial cytochrome c-oxidase, a complicated and highly regulated cellular process. Am J Physiol Cell Physiol 2006; 291:C1129-C1147. 